Published in final edited form as:

J Acad Nutr Diet. 2017 April ; 117(4): 599-608. doi:10.1016/j.jand.2016.11.005.

\title{
Meals Enhancing Nutrition after Discharge (MEND): Findings from a Pilot Randomized Controlled Trial
}

\author{
David R. Buys, PhD, MSPH, \\ Department of Food Science, Nutrition, and Health Promotion; Mississippi State University \\ Extension; and Mississippi Agriculture and Forestry Experiment Station Mississippi State \\ University, USA
}

Anthony D. Campbell, MSW, MA,

Department of Sociology, University of Alabama at Birmingham (UAB)

\author{
Alice Godfryd, BS, \\ Department of Healthcare Organization and Policy, UAB \\ Kellie Flood, MD, \\ Division of Gerontology, Geriatrics and Palliative Care, UAB \\ Elizabeth Kitchin, PhD, RD, \\ Department of Nutrition Sciences, UAB
}

\author{
Meredith L. Kilgore, PhD, RN, \\ Department of Health Care Organization and Policy, UAB, Birmingham, Alabama, USA
}

Sally Allocca, M.Div., and

PEER, Inc., Birmingham, AL

Julie L. Locher, PhD, MSPH

Division of Gerontology, Geriatrics, and Palliative Care, UAB, Birmingham, Alabama, USA; Comprehensive Center for Healthy Aging, UAB, Birmingham, Alabama, USA; Nutrition Obesity Research Center, UAB, Birmingham, Alabama, USA; Department of Health Care Organization and Policy, UAB, Birmingham, Alabama, USA

\section{Abstract}

Background-After older adults experience episodes of poor health or are hospitalized, they may not return to pre-morbid eating behaviors. Furthermore, poor nutrition increases hospital readmission risk, but evidence-based interventions addressing these risks are limited.

Objective-The pilot study's objective was to evaluate the feasibility of conducting a randomized controlled trial assessing a post-discharge home-delivered meals program's impact on older adults' nutritional intake and hospital readmissions and to assess patient acceptability and

Correspondence to: David R. Buys.

Publisher's Disclaimer: This is a PDF file of an unedited manuscript that has been accepted for publication. As a service to our customers we are providing this early version of the manuscript. The manuscript will undergo copyediting, typesetting, and review of the resulting proof before it is published in its final citable form. Please note that during the production process errors may be discovered which could affect the content, and all legal disclaimers that apply to the journal pertain. 
satisfaction with the program. The aims of the study were to 1) to evaluate successful recruitment, randomization, and retention of at least $80 \%$ of the 24 participants sought; 2 ) to compare the outcomes of hospital readmission and total daily caloric intake between participants in the intervention and control groups; and 3) to assess patient acceptability and satisfaction with the program.

Design-This study used a two-arm randomized controlled trial design, and baseline data were collected at enrollment; three 24-hour food recalls were collected during the intervention period; and health services utilization and intervention satisfaction was evaluated 45 days post-discharge.

Participants/setting-Twenty-four patients from the University of Alabama at Birmingham (UAB) Hospital's Acute Care for Elders Unit were enrolled from May 2014 to June 2015. They were 65 or older, at risk of malnutrition, cognitively intact, able to communicate, discharged to a place where the patient or family was responsible for preparing meals, and diagnosed with congestive heart failure, chronic obstructive pulmonary disease, acute myocardial infarction, or pneumonia. Final analysis included 21 participants.

Intervention-The intervention group received 10 days of home-delivered meals and nutrition education; the control group received usual care and nutrition education.

Main outcome measures-The main outcome was intervention feasibility, measured by recruitment and retention goals. Hospital readmissions, caloric intake, and satisfaction with the intervention were also evaluated.

Statistical analyses performed-Univariate and bivariate parametric statistics were used to evaluate differences between groups. Goals for success were identified to assess feasibility of conducting a full-scale study, and outcomes were measured against the goals.

Results- $87.5 \%$ of randomized participants were retained for final data collection, indicating that this intervention study is feasible. There were no significant differences between groups for hospital readmissions; however, caloric intake during the intervention period was greater for intervention vs. control participants (1595 vs. 1235, $p=.03$ ). Participants were overwhelmingly satisfied (82-100\% satisfied or very satisfied) with staff performance, meal quality, and delivery processes.

Conclusions-Conducting a randomized controlled trial to assess outcomes of providing homedelivered meals to older adults after hospital discharge in partnership with a small nonprofit organization is feasible and warrants future research.

\section{Keywords}

Older Adult Nutrition; Nutritional Risk; Home and Community-based Services; Home-delivered Meals

\section{INTRODUCTION}

Hospital readmissions affect one in six Medicare patients released following medical care and one in eight patients following surgery. ${ }^{1}$ It is estimated that these readmissions cost more than 17 billion US dollars. ${ }^{2}$ This is especially critical since Medicare "is the federal health insurance program for people who are 65 or older."3 Effective October 1, 2012, the 
Hospital Readmissions Reduction Program, mandated by the Patient Protection and Affordable Care Act, began reducing payments to hospitals that have excess readmissions. ${ }^{4}$ Concomitant with this change, several groups, including the Academy of Nutrition and Dietetics, have joined together to form The Alliance to Advance Patient Nutrition. The Alliance has as a major emphasis the elimination of hospital malnutrition through appropriate nutritional intervention, including interventions delivered at discharge. ${ }^{5}$

Krumholz recently described in The New England Journal of Medicine a "post-hospital syndrome" that is characterized by poor nutrition. ${ }^{6} \mathrm{He}$ noted post-hospital syndrome "receives little attention" and argued that strategies for mitigating the risk should include "promoting good nutrition and addressing nutritional deficiencies." ${ }^{6}$ Malnutrition occurs in $20-70 \%$ of older adults who are hospitalized and in up to $49 \%$ of older adults who have been recently discharged from the hospital. ${ }^{7}$ Previous work on this issue has found that older adults who experience nutritional risk are more likely to be subsequently hospitalized ${ }^{8}$ and that those discharged with malnutrition have higher risk of mortality within the year following their hospitalization. ${ }^{9}$ Furthermore, prior hospitalization has also been associated with poorer nutritional status. ${ }^{10}$ Vaudin and Sahyoun found that food anxiety was high among recently hospitalized older adults and was associated with poor health status. ${ }^{11}$ Concerns about post-discharge nutrition-related care persist in international contexts as well as the US, including in Australia, where one study found "few patients at nutrition risk received nutrition-focused care in the post-hospital period." 12 Other studies suggest that collaboration between different health services providers is an important step to addressing these concerns. ${ }^{13,14}$

Hospitals throughout the United States have responded to both changes in Medicare policy and increased recognition of the role of malnutrition in contributing to poorer health outcomes and potentially avoidable readmissions. They are now initiating many nutrition interventions, including hospital-to-home transition programs that sometimes include homedelivered meals. ${ }^{15,16}$ A systematic review evaluating whether home-delivered meals improves patient outcomes was recently published; no studies were identified that demonstrated an effect of home-delivered meals on hospital readmissions. ${ }^{15}$

Prior to conducting a full-scale study to test the hypothesis that providing home-delivered meals post-hospital discharge reduces older adults' risk for preventable readmissions, this pilot project was conducted with three aims: 1) to evaluate successful recruitment, randomization, and retention of at least $80 \%$ of the 24 participants sought; 2 ) to compare the outcomes of hospital readmission and total daily caloric intake between participants in the intervention and control groups; and 3) to assess patient acceptability and satisfaction with the program.

\section{MATERIALS AND METHODS}

The Meals Enhancing Nutrition After Discharge (MEND) pilot study was conducted between May 2014 and June 2015 at the University of Alabama at Birmingham (UAB) in collaboration with PEER (Promoting Empowerment and Enrichment Resources), Inc. ${ }^{17}$ The 
research protocol was approved by the UAB Institutional Review Board and all participants gave written informed consent.

\section{Sample}

Based on previous research regarding ideal sample size for the conduct of pilot studies, the investigators sought 24 participants for the study. ${ }^{18}$ Inclusion criteria required that participants be: 1) at least 65 years old, 2) able to communicate alone or through a caregiver, 3) discharged to a private residence or a facility where the patient was responsible for preparing their own meals, 4) at risk of malnutrition, defined as scoring less than 24 on the Mini Nutritional Assessment (MNA), ${ }^{19}$ and 5) have a diagnosis of congestive heart failure, chronic obstructive pulmonary disease, acute myocardial infarction, or pneumonia. These specific conditions were chosen because hospitals are now penalized under the Affordable Care Act for readmission within 30 days of discharge after an admission with these diagnoses. Penalties may include payment adjustments of up to $3 \%$ reduction in reimbursement. ${ }^{4}$ Exclusion criteria were: 1 ) a diagnosis of dementia (based on clinical reports from medical staff in rounds), 2) a terminal illness, 3) a cancer diagnosis within the last five years, 4) end-stage renal disease, 5) feeding tubes, 6) ventilator dependence, or 7) out of delivery range (more than 20 miles from PEER, Inc.).

\section{Recruitment}

Patients were recruited at the UAB Hospital Acute Care for Elders (ACE) Unit ${ }^{20}$ by graduate research assistants, in collaboration with full-time clinical staff on the Unit at daily rounds. Potentially eligible patients were screened and recruited at the bedside and provided written informed consent. Participants then completed the baseline assessment which was administered by research staff.

\section{Randomization}

Participants were assigned, based on a 1:1 allocation, to the intervention or control condition using a randomization schedule created from a computerized random number generating algorithm. To ensure allocation concealment from research staff prior to assignment, the randomization schedule was held by the PI's administrative assistant in sequentiallynumbered, opaque sealed envelopes. After assignment, the graduate research assistant or principal investigator notified the community partner, PEER, Inc., of participants who were assigned to receive meals.

\section{Control: Nutrition Education Group}

Control participants received the care or treatment as prescribed by their attending physician or nurse practitioner (usual care) and the "What's On Your Plate? Smart Food Choices for Healthy Aging" book created by the National Institute on Aging. ${ }^{21}$

\section{Intervention Arm: Nutrition Education + Home-delivered Meals Program}

In addition to usual care and receipt of What's On Your Plate?: Smart Choices for Healthy Aging, the intervention group received three meals per day for 10 days. Ten days was selected because that is what is currently being done by some insurers who are providing 
meals post-discharge. Meals were prepared by a local church and delivered by PEER, Inc., a local 501(c) 3 organization which serves a low-income neighborhood in Birmingham, AL, with programming around healthy lifestyles and access to healthy foods. Among other foodrelated programs ${ }^{22}$, the organization rents space from an urban church which has a health department-approved kitchen where it prepares and serves hot, nutritious meals Monday through Friday each week in a restaurant-style setting. The kitchen has two full-time cooks and a chef-consultant on-site who provides regular input into tasty, healthy meal preparation and service.

The daily meals provided to participants were from the hot lunch meal already being prepared at this location; they were delivered to participants Monday through Friday once per day, along with shelf-stable and refrigerated meals for breakfast and dinner. On Fridays, participants received two additional days of shelf-stable and refrigerated foods for the weekend. Meals were based upon National Institute on Aging's (NIA) recommendations from What's On Your Plate: Smart Choices for Healthy Aging ${ }^{21}$ and the Academy of Nutrition and Dietetics 2012 Position Statement on Food and Nutrition for Older Adults living in the community. ${ }^{23}$ Menus already being used by the kitchen were evaluated by a registered dietitian and health behavior expert, and additional meals were added to the menu for the kitchen staff to use in preparing foods for these participants. The dietitian helped design these meals to enhance the menu. The menu items were chosen with an emphasis on cultural appeal, taste, familiarity, and nutritional quality. Two dietetic interns from UAB in placements at PEER, Inc. were involved in accommodating participants with special dietary requirements. For example, participants requiring diabetic or low-sodium diets received meals prepared specifically for their needs.

\section{Baseline Assessment}

The assessment tools were selected based on recommendations from the Institute of Medicine Committee on Nutrition Services for Medicare Beneficiaries to evaluate community-dwelling older adults ${ }^{24}$ and on previous studies. ${ }^{10,25}$ These instruments evaluated factors related to nutritional status (Mini Nutritional Assessment (MNA), ${ }^{19}$ ) and food insecurity (United Stated Department of Agriculture Food Security Assessment ${ }^{26}$ ) as well as the OASIS Support questionnaire which assessed caregiver support by asking participants about who provides social support, who is the person who provides lead responsibility for support, and how often support is provided. These items were obtained from a comprehensive assessment for home care patients required by Medicare to measure patient outcomes for purposes of outcome-based quality improvements. ${ }^{27}$ Patients were also asked about available resources for in-home food preparation, health services utilization (i.e.: visits to a healthcare provider, emergency room, or hospital in the past 30 days), contact information of two relatives or friends, and demographic information, including poverty. Poverty level was assessed by asking participants if their income is greater or less than the monthly threshold set by the US Census in $2014(\$ 946)^{28}$ and recorded as yes/no. Weight and height were collected from participants' charts and were used to calculate BMI which was categorized into standard categories for the general population ${ }^{29}$ and into categories adjusted for older adults based on the work on Winter et al. ${ }^{30}$ The assessment took an average of 30 minutes to complete. Additionally, all participants were called three 
times within 10 days of discharge to collect 24-hour food recalls; each participant was called on one weekend day and two week days. Recalls were collected by certified technicians at UAB's Survey Research Unit. Data were directly entered into the Nutrition Data System for Research (NDSR) software system. ${ }^{31}$ The NDSR multi-pass protocol was used. The NDSR Food and Nutrient Database includes over 18,000 foods with 8,000 brand name products and ingredient choices and preparation methods that provide more than 160,000 food variants. Values for 165 nutrient, nutrient ratios and other food components are generated from the database. ${ }^{32-34}$ Total caloric intake was the primary variable of interest for this project, and data reported on caloric intake represents the mean of the three recalls for each participant.

\section{Follow-up Assessment}

The follow-up assessment was conducted by phone from the UAB Survey Research Unit 45 days following the date the patient was discharged to home and consisted of the health services utilization questionnaire that was administered at baseline to assess for hospital readmissions. Participants who received the intervention also responded to a satisfaction assessment which included questions about satisfaction with study staff, meal quality, and the delivery process with standard Likert scale response options. Participants were also given the opportunity to identify positive aspects of the program as well as offer suggestions for how to improve the program via open-ended qualitative questions.

\section{Additional Process Measures}

The number of meals prepared and miles driven for delivery was also recorded to aid in determining the true costs of the intervention.

\section{Outcomes and Analyses}

After confirming that continuous level data met the assumptions of normality using the Shapiro-Wilk test, intervention and control groups were compared using the chi-square statistic and two-sample t-tests to evaluate balance in the randomization arms. Results were considered statistically significant if $p<.05$. The means and standard deviations of continuous variables and numbers and percentages of categorical variables are reported (Table 1.). The key outcomes of interest were feasibility of recruitment, randomization, and retention of participants for the study; this was evaluated using simple comparison against the goal of $80 \%$ retention. Furthermore, process measures, including data related to the delivery was also collected including the number of meals prepared, deliveries completed, and miles driven; these were calculated using simple summary characteristics. Regarding the second aim, the outcomes of hospital readmissions and caloric intake were evaluated using the chi-square test and two-sample t-test, respectively. Third, simple summary statistics were used to examine satisfaction as measured with quantitative and qualitative responses. All data management and analyses were conducted using SPSS. ${ }^{35}$

\section{RESULTS}

Twenty-four participants were recruited and randomized into the study (Figure 1.) between May 2014 and June 2015. There were no differences observed between groups at baseline (Table 1.). Participants' primary diagnoses consisted of congestive heart failure, pneumonia, 
and chronic obstructive pulmonary disease; patients with acute myocardial infarction were referred to a cardiac unit and are not seen on the floor where recruitment was being conducted. Other characteristics are reported in Table 1.

One of the 12 participants randomized into the intervention arm was re-hospitalized prior to meal delivery and unable to receive the meals during the intervention period. Therefore, 11 participants received 330 meals total during the intervention period. Meal delivery required driving 1459 total miles, for 76 total deliveries total at an average of 19.2 miles per delivery.

Follow-up data at 45 days was successfully collected from 11 (91.7\%) participants in the intervention group and $10(83.3 \%)$ participants in the control group, with an overall retention rate of $87.5 \%$ (See Figure 1.). Among participants in the intervention group, three (27.7\%) were readmitted to the hospital within 30 days of discharge compared with one participant $(8.3 \%)$ in the control group ( $p=.59)$. Participants randomized to the intervention group reported consuming an average of 1595 calories (SD: 312) during the 10-day post-discharge intervention period compared with an average of 1235 (SD: 456) calories reported by participants in the control group $(\mathrm{p}=.03)$.

PEER, Inc. charged $\$ 12$ per day for the food and delivery and limited delivery to within 20 miles of their location. Between $82 \%$ and $100 \%$ of participants who received meals and completed the questionnaire reported satisfaction with multiple indicators of staff performance, meal quality, and the delivery process; one participant indicated a need for improvement with regard to the following: feeling connected to the staff, appeal of the food, healthiness of the food, level of frozen-ness of the food, and set-up of the meals (Table 2.). Furthermore, responses to open-ended questions on the satisfaction assessment revealed similar levels of satisfaction with some suggestions for improvement. One participant said, "The food was very good and they worked with me around the kinds of food I like;" another participant told interviewers that if [participant's] daughter had a doctor's appointment [daughter] did not have to come in and try to prepare something for [participant] to eat. Investigators surmised that participants may be sharing their meals with others in the household, especially among families where food insecurity levels may be high. One participant indicated this was true: "I especially liked being able to share the food with other people in my household." Another caregiver told interviewers that the participant was eating and doing very well; and [participant] felt that the meals helped to get back into the swing of things, as far as [participant's] eating. Furthermore, the caregiver said that the participant "informed the meal deliverer of the foods [participant] did not eat and they didn't bring any more" indicating that being responsive to participants' preferences is important. When asked about what should change, one participant replied: "I wish the program could continue long term." Another participant said, "The deliverer of the meals was always in a hurry, in and out." Participants also indicated a desire for more variety in the fruits and vegetables and a concern about how diabetic-friendly the meals were.

\section{DISCUSSION}

The overarching goal of the study was met, demonstrating that partnering with a nonprofit organization to provide meals to nutritionally vulnerable older adults after hospital discharge 
is feasible, and moreover, that recruiting, randomizing, and retaining participants in a study with such an intervention can be completed. Previous research has shown that among older adults being discharged from the hospital, $35 \%$ reported an inability to both prepare meals and shop for food. ${ }^{36}$ Interventions such as this one that addresses this risk may have a significant impact on recovery and risk of readmissions, and this is especially important given the current penalties being levied against hospitals for preventable readmissions. ${ }^{4}$ While this feasibility study did not show an impact on readmissions, Cho, et al. did so with a similar intervention; they demonstrated that provision of one home-delivered meal per day through traditional means like Meals on Wheels, beginning nearly 9 days post-discharge, can have an effect on hospital readmission rates. ${ }^{37}$ No other studies before this one have demonstrated a partnership between an academic medical center and a community-based non-profit organization like PEER, Inc. for the purpose of providing meals to older adults immediately after discharge. In this study, participants received three meals per day, beginning within one day of leaving the hospital.

Of note, especially given the small sample size, is that the participants receiving the intervention consumed 360 more calories per day than those in the control group ( $\mathrm{p}=.03$ ). This study did not show any statistical differences in hospital readmission, however. In fact, more participants from the intervention group were readmitted to the hospital compared with the control group. While this may be explained by the small sample size, it may also, in part, be explained by other circumstances such as severity of diagnosis and complications from comorbid illnesses, which were not measured or adjusted for in this study. In fact, the primary difference may have been related to the fact that the intervention group had more persons with diabetes; after enrollment in the study, staff learned of two participants who had diabetes and suffered from related complications which led to their rehospitalization. Because investigators did not randomize or stratify according to disease severity or comorbidity, the randomization scheme did not adjust for these. Future studies would benefit from accounting for such relevant comorbidities using stratified randomization schemes.

With respect to the composition of the study sample, the investigators note that many people had to be screened and interviewed before enrolling in the study (Figure 1). The most common reason that otherwise eligible patients gave for declining to participate in the study was having adequate support at home, especially from spouses. Thus, the sample consisted of mostly widowed, divorced, or single individuals who expressed a need for additional support. Another related reason for non-participation was having sufficient financial resources for purchasing food. This led to the sample being composed of mostly individuals below poverty level. Given these observations, the program particularly addressed the needs of low-income individuals living alone in the community.

\section{Limitations and Considerations for Future Research}

Because the purpose of this study was to demonstrate feasibility and ultimately ability to conduct a large-scale randomized controlled trial of a project like this, it is important to consider limitations and what should be done differently in future work. First, while the investigators were successful in developing and maintaining the partnership with PEER, Inc. and in recruiting the participants needed for this study from UAB Hospital's ACE Unit, 
recruitment for the 24 participants in this study took more than one year, possibly due to the limited scope of the recruitment criteria. Alternative strategies for recruitment might be considered such as recruiting from multiple units in a hospital or from multiple hospitals and expanding the diagnoses for which this intervention is provided in the interest of limiting readmissions for any reason rather than just for the ones identified for this study. The pilot study helped demonstrate that low-resource patients are the ones for whom this intervention is appealing; therefore offering it based on nutritional risk, including having limited resources, may be more appropriate. Second, PEER, Inc. likely underestimated the cost of the services, which they indicated would be $\$ 12$ per day. Reimbursement for mileage alone should have been $\$ 11.04$ (19.2 miles per delivery $* \$ 0.575$ per mile) per day based on the federal mileage reimbursement rate at the time of the study. Additional costs for each meal and delivery should be allocated in future studies. Third, PEER, Inc. was limited to traveling within 20 miles of their location, which excluded many patients from enrolling in the study who were otherwise eligible to participate. Therefore, the investigators recognize that a fullscale intervention would benefit from enlisting multiple partners in communities around the region. Additionally, while the investigators had success with data collection with the current limited selection of variables assessed, the investigators might also directly assess BMI at baseline as one indicator of nutritional health rather than relying on data in the participants' charts. Furthermore, follow-up assessment of the MNA may help measure success of the intervention as it would allow investigators to assess change from baseline. Also, given the limitations of using food recall data as an outcome variable, the investigators view this as a process variable that lends some support that the intervention was working as intended (i.e., participants who received meals actually ate them). ${ }^{38,39}$ Finally, comments collected during the satisfaction assessment indicate that intervention participants were overwhelmingly satisfied with the resources they received. They may also need more nutrition services and additional resources after discharge from the hospital, including additional nutritional support and companion care. ${ }^{40}$

Of note, while these are outside the scope of this current project the full-scale study should consider examining dose response of the meals to better understand how many meals postdischarge has the optimal effect. Furthermore and finally, it will be crucial to evaluate the cost effectiveness of this intervention along with other approaches to providing postdischarge nutritional support for high risk older adults.

\section{CONCLUSION}

Conducting a randomized controlled trial to assess the outcomes of providing homedelivered meals to older adults after discharge from the hospital in partnership with a small nonprofit organization is feasible, but not without challenges. In the pilot phase, participants agreed to participate and matriculated through the study according to its goals; responded to baseline and follow-up questions, indicating that the intervention had a positive effect on caloric intake; and for those receiving the intervention, reported overwhelming satisfaction with the home-delivered meal services. Future research should engage more inclusive recruiting strategies, including enrolling people with more diagnoses. Additionally, other community partners similar to PEER, Inc. should be engaged to ensure that people in geographically diverse areas who are otherwise eligible for participation are served. 


\section{Acknowledgments}

\section{FUNDING}

This project was supported by a grant from the University of Alabama at Birmingham Comprehensive Center for Healthy Aging.

[Blinded for Review] is supported in part by the Mississippi Agricultural and Forestry Experiment Station at Mississippi State University.

[Blinded for Review] is supported by the National Institutes on Aging through a K07 Career Academic Leadership Award (K07AG043588).

\section{References}

1. Goodman, DC., Fisher, ES., Chang, C-H. [Accessed September 4, 2015] The Revolving Door: A Report on US Hospital Readmissions. 2013. http://www.rwjf.org/content/dam/farm/reports/reports/ 2013/rwjf404178

2. Rau, J. [Accessed September 5, 2015] Medicare To Penalize 2,217 Hospitals For Excess Readmissions. Kaiser Health News. 2012. http://khn.org/news/medicare-hospitals-readmissionspenalties/

3. [Accessed April 27, 2016] What's Medicare?. 2016. https://www.medicare.gov/sign-up-changeplans/decide-how-to-get-medicare/whats-medicare/what-is-medicare.html

4. Patient Protection and Affordable Care Act, 42 U.S.C. $§ 18001$ et seq. (2010).

5. [Accessed September 8, 2015] Building a Consensus for Better Patient Outcomes. 2015. http:// malnutrition.com/consensuspaper

6. Krumholz HM. Post-Hospital Syndrome - An Acquired, Transient Condition of Generalized Risk. N Engl J Med. 2013; 368(2):100-102. [PubMed: 23301730]

7. Heersink JT, Brown CJ, Dimaria-Ghalili RA, Locher JL. Undernutrition in hospitalized older adults: patterns and correlates, outcomes, and opportunities for intervention with a focus on processes of care. J Nutr Elder. 2010; 29(1):4-41. [PubMed: 20391041]

8. Buys DR, Roth DL, Ritchie CS, et al. Nutritional Risk and Body Mass Index Predict Hospitalization, Nursing Home Admissions, and Mortality in Community-Dwelling Older Adults: Results From the UAB Study of Aging With 8.5 Years of Follow-Up. The Journals of Gerontology Series A: Biological Sciences and Medical Sciences. 2014

9. Liu L, Bopp MM, Roberson PK, Sullivan DH. Undernutrition and Risk of Mortality in Elderly Patients Within 1 Year of Hospital Discharge. The Journals of Gerontology Series A: Biological Sciences and Medical Sciences. 2002; 57(11):M741-M746.

10. Locher JL, Ritchie CS, Robinson CO, Roth DL, Smith West D, Burgio KL. A multidimensional approach to understanding under-eating in homebound older adults: the importance of social factors. Gerontologist. 2008; 48(2):223-234. [PubMed: 18483434]

11. Vaudin A, Sahyoun NR. Food Anxiety Is Associated with Poor Health Status Among Recently Hospital-Discharged Older Adults. J Nutr Gerontol Geriatr. 2015; 34(2):245-262. [PubMed: 26106991]

12. Young A, Mudge A, Banks M, et al. From Hospital to Home: Limited Nutritional and Functional Recovery for Older Adults. The Journal of Frailty and Aging. 2015; 4(2):69. [PubMed: 27032047]

13. Marshall S, Bauer J, Isenring E. The consequences of malnutrition following discharge from rehabilitation to the community: a systematic review of current evidence in older adults. J Hum Nutr Diet. 2014; 27(2):133-141. [PubMed: 24289811]

14. Marshall S, Young A, Bauer J, Isenring E. Malnourished older adults admitted to rehabilitation in rural New South Wales remain malnourished throughout rehabilitation and once discharged back to the community: A prospective cohort study. Journal of Aging Research and Clinical Practice. 2015; 4(4):197-204. 
15. Campbell AD, Godfryd A, Buys DR, Locher JL. Does Participation in Home-Delivered Meals Programs Improve Outcomes for Older Adults? Results of a Systematic Review. J Nutr Gerontol Geriatr. 2015; 34(2):124-167. [PubMed: 26106985]

16. Oria, M., Cappelucci, K., Rodgers, A., Rapporteurs, AV. Meeting the Dietary Needs of Older Adults: Workshop in Brief. The National Academies Press; 2016.

17. P.E.E.R., Inc. [Accessed August 8, 2016] 2016. http://www.eastlakemarket.org/tag/p-e-e-r-inc/

18. Julious SA. Sample size of 12 per group rule of thumb for a pilot study. Pharm Stat. 2005; 4(4): 287-291.

19. Guigoz Y, Vellas B. The Mini Nutritional Assessment (MNA) for grading the nutritional state of elderly patients: presentation of the MNA, history and validation. Nestle Nutr Workshop Ser Clin Perform Programme. 1999; 1:3-11. discussion 11-12.

20. Flood KL, MacLennan PA, McGrew D, Green D, Dodd C, Brown CJ. EFfects of an acute care for elders unit on costs and 30-day readmissions. JAMA Internal Medicine. 2013; 173(11):981-987. [PubMed: 23609002]

21. What's on Your Plate?: Smart Food Choices for Healthy Aging. National Institute on Aging, National Istitutes of Health, U.S. Department of Health and Human Services; 2011.

22. Dover SE, Buys DR, Allocca S, Locher JL. Farmers' Market Produce Delivery Program for Mitigating Nutritional Risk in Older Adults. J Hunger Environ Nutr. 2013; 8(1):106-108.

23. Bernstein M, Munoz N. Position of the Academy of Nutrition and Dietetics: Food and Nutrition for Older Adults: Promoting Health and Wellness. J Acad Nutr Diet. 2012; 112(8):1255-1277. [PubMed: 22818734]

24. Committee on Nutrition Services for Medicare B, Food and Nutrition B. The Role of Nutrition in Maintaining Health in the Nation's Elderly:Evaluating Coverage of Nutrition Services for the Medicare Population. The National Academies Press; 2000.

25. Locher JL, Ritchie CS, Roth DL, Sen B, Vickers KS, Vailas LI. Food choice among homebound older adults: motivations and perceived barriers. J Nutr Health Aging. 2009; 13(8):659-664. [PubMed: 19657547]

26. [Accessed June 24, 2014] Food Security in the US: Survey Tools. 2012. http://www.ers.usda.gov/ topics/food-nutrition-assistance/food-security-in-the-us/survey-tools.aspx\#.UV350qKG3eA

27. Outcome and Assessment Information Set (OASIS). U.S. Department of Health and Human Services, Centers for Medicare \& Medicaid Services; https://www.cms.gov/Medicare/QualityInitiatives-Patient-Assessment-Instruments/OASIS/index.html [Accessed September 10, 2014]

28. Bureau UC. Bureau UC. Poverty Thresholds. Washington, DC: 2014.

29. [Accessed August 5, 2016] About Adult BMI. 2016. https://www.cdc.gov/healthyweight/ assessing/bmi/adult_bmi/

30. Winter JE, MacInnis RJ, Wattanapenpaiboon N, Nowson CA. BMI and all-cause mortality in older adults: a meta-analysis. The American Journal of Clinical Nutrition. 2014; 99(4):875-890. [PubMed: 24452240]

31. Nutrition Data System for Research [computer program]. Version 2014. Minneapolis, MN: Nutrition Coordinating Center; 2014.

32. Dennis B, Ernst N, Hjortland M, Tillotson J, Grambsch V. The NHLBI nutrition data system. J Am Diet Assoc. 1980; 77(6):641-647. [PubMed: 6893713]

33. Schakel SF. Maintaining a Nutrient Database in a Changing Marketplace: Keeping Pace with Changing Food Products-A Research Perspective. J Food Compost Anal. 2001; 14(3):315-322.

34. Harnack L, Stevens M, Van Heel N, Schakel S, Dwyer JT, Himes J. A computer-based approach for assessing dietary supplement use in conjunction with dietary recalls. J Food Compost Anal. 2008; 21(Supplement):S78-S82. [PubMed: 19190705]

35. IBM SPSS Statistics for Windows [computer program]. Version 24. Armonk, NY: IBM Corporation; 2015.

36. Anyanwu UO, Sharkey JR, Jackson RT, Sahyoun NR. Home Food Environment of Older Adults Transitioning From Hospital to Home. J Nutr Gerontol Geriatr. 2011; 30(2):105-121. [PubMed: 21598161] 
37. Cho J, Thorud JL, Marishak-Simon S, Frawley L, Stevens AB. A Model Home-Delivered Meals Program to Support Transitions from Hospital to Home. J Nutr Gerontol Geriatr. 2015; 34(2):207217. [PubMed: 26106988]

38. Dhurandhar NV, Schoeller D, Brown AW, et al. Energy balance measurement: when something is not better than nothing. Int J Obes. 2015; 39(7):1109-1113.

39. Subar AF, Freedman LS, Tooze JA, et al. Addressing Current Criticism Regarding the Value of Self-Report Dietary Data. The Journal of Nutrition. 2015; 145(12):2639-2645. [PubMed: 26468491]

40. Thomas KS, Akobundu U, Dosa D. More Than A Meal? A Randomized Control Trial Comparing the Effects of Home-Delivered Meals Programs on Participants' Feelings of Loneliness. The Journals of Gerontology Series B: Psychological Sciences and Social Sciences. 2015 


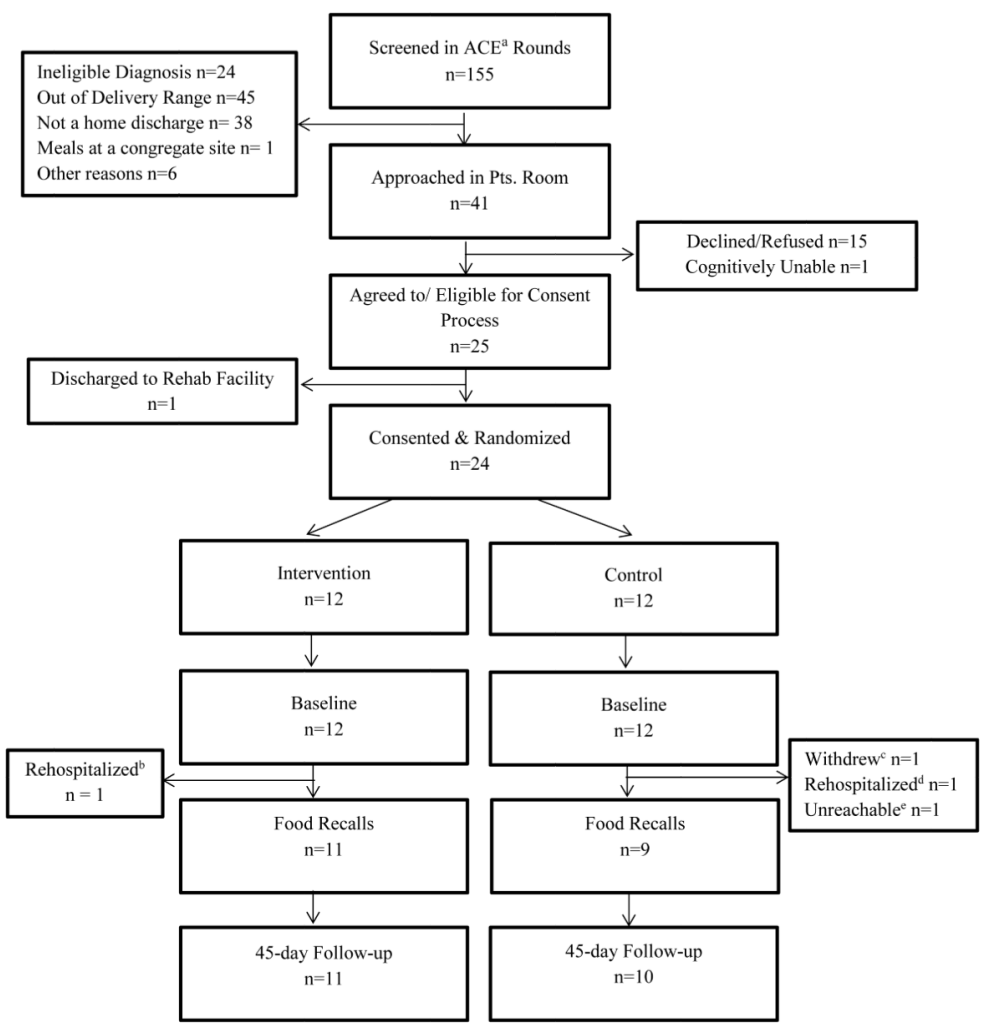

Figure 1.

Flow Diagram of Study Participants throughout the MEALS ENHANCING NUTRITION AFTER DISCHARGE (MEND) Study

${ }^{a}$ Acute Care for Elders Unit

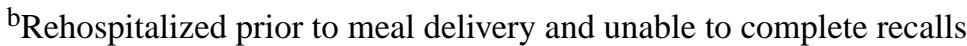

${ }^{\mathrm{c}}$ Withdrew and did not complete recalls

${ }^{\mathrm{d}}$ Rehospitalized and unable to complete recalls

eUnable to reach participant to complete recalls but able to reach for 45-day follow-up 


\section{Table 1}

Baseline Demographic Characteristics, According to Study Group for the Meals Enhancing Nutrition After Discharge (MEND) Study ${ }^{a}$

\begin{tabular}{|c|c|c|c|}
\hline Variable & Entire Sample (N=24) & $\begin{array}{l}\text { Home- delivered Meals } \\
\text { Intervention }(\mathrm{N}=12)\end{array}$ & $\begin{array}{l}\text { Standard Care Control } \\
(\mathrm{N}=12)\end{array}$ \\
\hline Age - years & $77.2 \pm 9.6$ & $75.8 \pm 9.1$ & $78.6 \pm 10.2$ \\
\hline Male Sex - no. (\%) & $6(25.0)$ & $2(16.7)$ & $4(33.3)$ \\
\hline \multicolumn{4}{|l|}{ Race/Ethnicity } \\
\hline Non-Hispanic Black/African American - no. (\%) & $20(83.3)$ & $10(83.3)$ & $10(83.3)$ \\
\hline Non-Hispanic White - no. (\%) & $4(16.7)$ & $2(16.7)$ & $2(16.7)$ \\
\hline \multicolumn{4}{|l|}{ Education } \\
\hline Less than high school - no. $(\%)$ & $11(45.8)$ & $6(50.0)$ & $5(41.7)$ \\
\hline High school - no. (\%) & $4(16.7)$ & $3(25.0)$ & $1(8.3)$ \\
\hline Some college - no. $(\%)$ & $7(29.2)$ & $2(16.7)$ & $5(41.7)$ \\
\hline College graduate - no. $(\%)$ & $2(8.3)$ & $1(8.3)$ & $1(8.3)$ \\
\hline Income below poverty level $b_{-}$no. (\%) & $15(62.5)$ & $8(66.7)$ & $7(58.3)$ \\
\hline \multicolumn{4}{|l|}{ Marital Status } \\
\hline Married - no. (\%) & $3(12.5)$ & $0(0.0)$ & $3(25.0)$ \\
\hline Widowed - no. $(\%)$ & $12(50.0)$ & $8(66.7)$ & $4(33.3)$ \\
\hline Divorced - no. (\%) & $8(33.3)$ & $4(33.3)$ & $4(33.3)$ \\
\hline Never Married - no. $(\%)$ & $1(4.2)$ & $0(0.0)$ & $1(8.3)$ \\
\hline \multicolumn{4}{|l|}{ Living Situation } \\
\hline Lives alone - no. $(\%)$ & $11(45.8)$ & $7(58.3)$ & $4(33.3)$ \\
\hline Lives with spouse - no. (\%) & $3(12.5)$ & $0(0.0)$ & $3(25.0)$ \\
\hline Lives with other family - no. (\%) & $10(41.7)$ & $5(41.7)$ & $5(41.7)$ \\
\hline Weight in $\mathrm{kg}$ & $77.2 \pm 18.8$ & $85.7 \pm 15.7$ & $68.7 \pm 18.3$ \\
\hline BMI & $27.2 \pm 6.9$ & $29.9 \pm 7.3$ & $24.5 \pm 5.6$ \\
\hline \multicolumn{4}{|l|}{ BMI Categories } \\
\hline Underweight $(<18.5)-$ no. $(\%)$ & $2(8.3)$ & $0(0.0)$ & $2(16.7)$ \\
\hline Normal Weight (18.5-24.9) - no. (\%) & $9(37.5)$ & $4(33.3)$ & $5(41.7)$ \\
\hline Overweight (25-29.9) - no. (\%) & $5(20.8)$ & $3(25.0)$ & $2(16.7)$ \\
\hline Obese ( 230$)-$ no. $(\%)$ & $8(33.3)$ & $5(41.7)$ & $3(25.0)$ \\
\hline \multicolumn{4}{|l|}{ BMI Adjusted Categories ${ }^{c}$} \\
\hline Low $(<23)-$ no. $(\%)$ & $8(33.3)$ & $2(16.7)$ & $6(50)$ \\
\hline Other $(23+)-$ no. $(\%)$ & $16(66.7)$ & $10(83.3)$ & $6(50)$ \\
\hline \multicolumn{4}{|l|}{ Food Security $d$} \\
\hline High or Marginal - no. (\%) & $15(62.5)$ & $7(58.3)$ & $8(67.0)$ \\
\hline Low - no. $(\%)$ & $5(20.8)$ & $3(25.0)$ & $2(16.7)$ \\
\hline Very Low - no. $(\%)$ & $4(16.7)$ & $2(16.7)$ & $2(16.7)$ \\
\hline Medical Diagnoses & & & \\
\hline
\end{tabular}




\begin{tabular}{|l|l|l|l|}
\hline Variable & Entire Sample (N=24) & $\begin{array}{l}\text { Home- delivered Meals } \\
\text { Intervention }(\mathbf{N}=\mathbf{1 2})\end{array}$ & $\begin{array}{l}\text { Standard Care Control } \\
(\mathbf{N}=\mathbf{1 2})\end{array}$ \\
\hline Congestive Heart Failure - no. $(\%)$ & $9(37.5)$ & $4(33.3)$ & $5(41.7)$ \\
\hline Pneumonia - no. $(\%)$ & $10(41.7)$ & $5(41.7)$ & $5(41.7)$ \\
\hline Chronic Obstructive Pulmonary Disease - no. $(\%)$ & $5(20.8)$ & $3(25.0)$ & $2(16.7)$ \\
\hline Acute Myocardial Infarction - no. $(\%)$ & $0(0.0)$ & $0(0.0)$ & $0(0.0)$ \\
\hline
\end{tabular}

${ }^{a}$ Plus-minus values are means \pm standard deviations. All demographic information was based upon self-report. There were no significant differences between the groups at a $\mathrm{p}<0.05$.

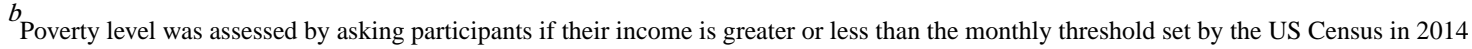
$(\$ 946)^{28}$ and recorded as yes/no.

${ }^{c}$ Adjusted BMI Categories are based on the work of Winter et al. $(2014)^{30}$, suggesting that for older adults with BMI $<23$, there is a significant risk of mortality.

$d_{\text {Food Security was evaluated using the USDA Food Security Assessment (Food Security in the US: Survey Tools, 2012) }}^{26}$. 


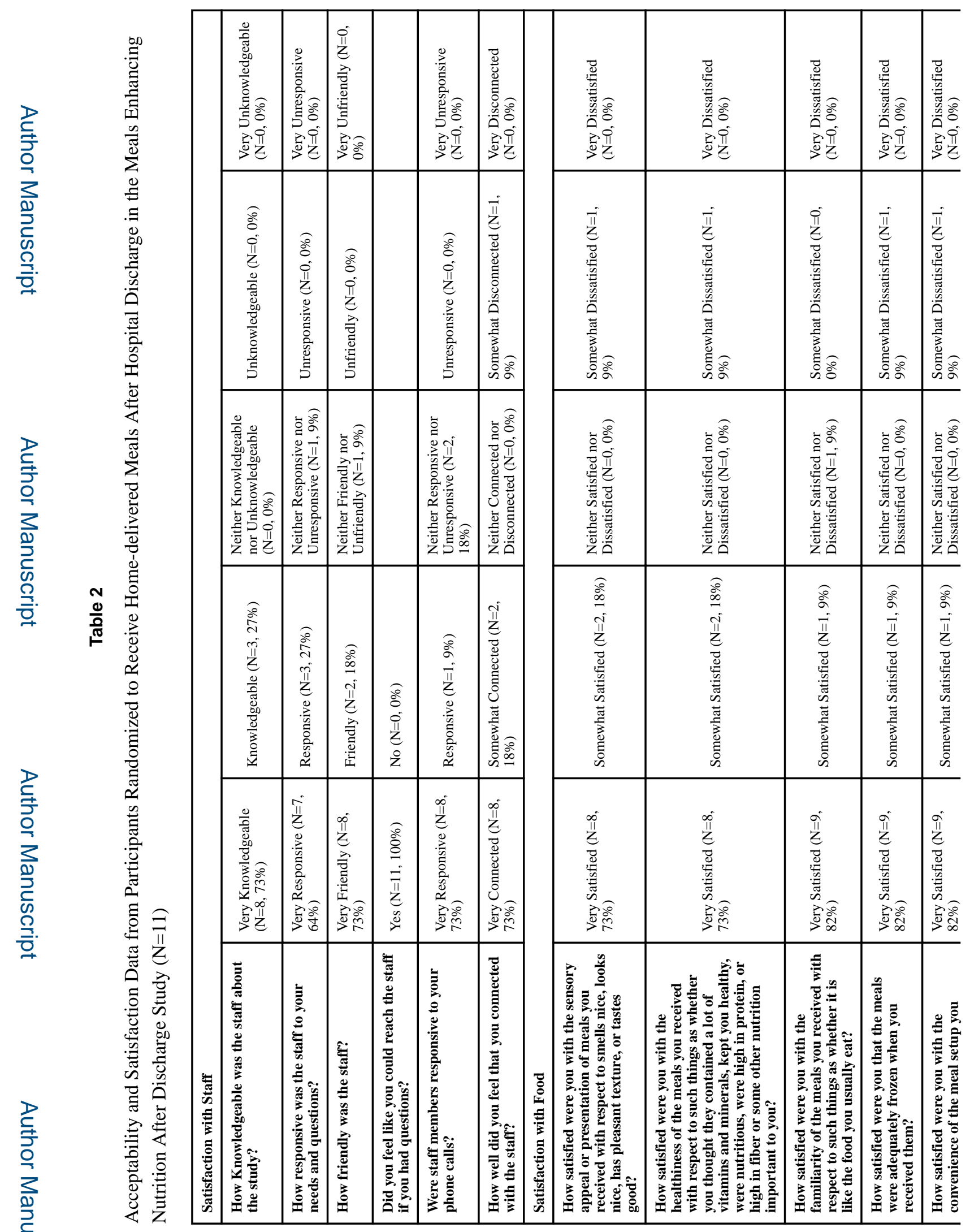

J Acad Nutr Diet. Author manuscript; available in PMC 2018 April 01. 


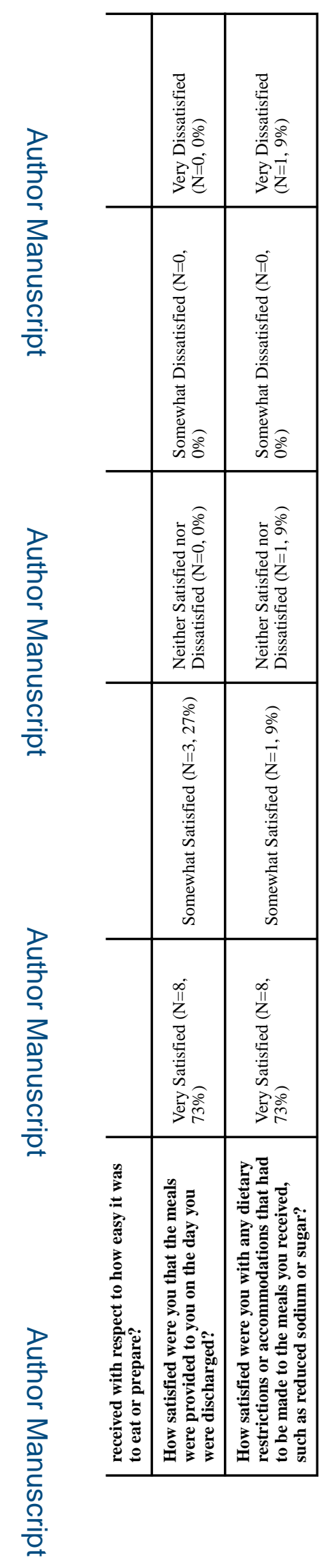

